\title{
SER LIVRO, SER HÍBRIDO, SER LITERATURA: UMA ANÁLISE DA CATEGORIZAÇÃO DE OBRAS LITERÁRIAS JUVENIS ASSINADAS POR INFLUENCIADORES DIGITAIS (2008 - 2016)
}

To be a book, to be hybrid, to be literature: An analysis of the categorization of youth literary works signed by digital influencers (2008 - 2016)

Jennifer da Silva Gramiani CELESTE Programa de Pós-Graduação em Estudos Literários Universidade Federal de Juiz de Fora djeceleste@gmail.com https://orcid.org/0000-0001-7869-4522

Rogério de Souza Sérgio FERREIRA Programa de Pós-Graduação em Estudos Literários Universidade Federal de Juiz de Fora rogeriossferreira@gmail.com https://orcid.org/0000-0002-6365-9772

RESUMO: Os lançamentos literários impressos da autoria de influenciadores digitais adolescentes, entre blogueiros e youtubers, seguramente contribuiu ao aquecimento do nicho de consumo dedicado ao público jovem, em grande parcela órfão de publicações cativas às temáticas presentes em seus cotidianos, assinadas por pares - ídolos da Web. Um levantamento de obras impressas produzidas por administradores de blogs e canais do YouTube, entre janeiro de 2008 e dezembro de 2016, trouxera-nos à tona relevantes achados no que concerne à divergência entre dados catalográficos e os gêneros de fato contemplados nos livros analisados. Essa ocorrência nos conduz a refletir a respeito das dificuldades de classificação dos conteúdos abordados pelos jovens autores no mundo do papel, processo esse mediado pelo mercado editorial. Logo, pretendemos apresentar considerações gerais sobre tal problemática, lançando luzes e perspectivas à produção literária brasileira contemporânea cujo público-alvo é constituído por sujeitos ainda em processo de formação enquanto leitores, amantes dos seres e estares dessa Literatura. Utilizamos como base o supracitado mapeamento, ademais, aportes teóricos pertinentes ao campo temático, convictos de

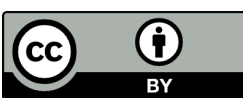


que as manifestações ciberespaciais têm transfigurado a arte literária, agora, mais do que nunca, plural e conectada às próprias possibilidades. PALAVRAS-CHAVE: Literatura Juvenil; Mercado Editorial; Internet; Blogueiros; Youtubers.

\begin{abstract}
The printed literary releases by adolescent digital influencers, among bloggers and youtubers, certainly contributed to the heating of the consumer niche dedicated to young audiences, in large part orphaned by publications captive to the themes present in their daily lives, signed by idol pairs. A survey of printed works produced by administrators of blogs and YouTube channels, between January 2008 and December 2016, brought to light relevant findings regarding the divergence between catalog data and the genres actually covered in the books analyzed. This occurrence leads us to reflect on the difficulties in classifying the content addressed by young authors in the paper world, a process mediated by the publishing market. Therefore, we intend to present general considerations about this problem, shedding light and perspectives on contemporary Brazilian literary production whose target audience is made up of subjects still in the process of being formed as readers, fall in love with this Literature. We use as a basis the above-mentioned mapping, in addition, theoretical contributions relevant to the thematic field, convinced that cyberspace manifestations have transformed literary art, now, more than ever, plural and connected to the possibilities themselves. KEYWORDS: Youth Literature; Editorial Market; Internet; Bloggers; Youtubers.
\end{abstract}

\title{
INTRODUÇÃO
}

Contrário às expectativas apocalípticas outrora depositadas sobre os rumos e o futuro da Literatura na era digital, o movimento de publicação impressa liderado por blogueiros e youtubers adolescentes demonstrara a aptidão que detém a arte literária de conviver e coniver com a revolução imposta pelas novas tecnologias eletrônicas, já que os supramencionados sujeitos, agora também autores de seus próprios livros, emergiram do ciberespaço e trouxeram ao saber uma dinâmica literária até então desconhecida do mercado editorial, o qual tivera de se adaptar à demanda sociocultural e contemporânea, contatando e contratando tais indivíduos, transpondo seus conteúdos a priori produzidos no universo das telas às páginas dos livros manufaturados sob os moldes tradicionais. Reconstruir o mundo do papel, desde muito tempo apreciado por adeptos às práticas de leitura, decerto se configurou como desafio inimaginável ao nicho de consumo dedicado ao público adolescente, hipoteticamente cativo à liquidez inerente à contemporaneidade. 
Ler aquilo o que seus ídolos virtuais têm para os narrar é uma exigência de tempos nos quais os quinze minutos de fama já não são mais capazes de suprir o desejo de ocupar um lugar social para chamá-lo de seu. Deter um livro impresso assinado por aquele que lhe comunica por intermédio das telas dos notebooks, tablets ou smartphones é receber um alento inestimável nesta temporalidade, na qual as tensões entre analógico e digital intentam se anular a fim de conceder espaço às manifestações de múltiplas naturezas.

Com isso, chegam-nos as novidades. Por ser essa uma dinâmica ainda em estado de crescente exploração, é até certo ponto compreensível identificarmos problemáticas a respeito das categorizações dos tais livros da autoria de jovens blogueiros e youtubers. Ao nos debruçarmos em levantamento de obras de papel provenientes do meio online lançadas entre janeiro de 2008 e dezembro de 2016, verificamos algumas divergências acerca das categorizações propostas pelas editoras. Essa ocorrência auxilia-nos a pensar sobre a real constituição da Literatura Juvenil produzida por internautas e àquilo o que é sujeita aos olhos do mercado que a comercializa. Isso, pois, culmina em uma reflexão atinente ao território sagrado o qual passa a ser progressivamente invadido, ocupado e desnudado por aqueles que já haviam sido acostumados a recepcionar títulos assinados por indivíduos que lhes escreviam sob a perspectiva dos adultos ou, ainda, por tantos outros oriundos de solos estrangeiros. Mediante o quadro exposto, almejamos propor discussão tangente ao referido impasse, observado a partir da análise de mapeamento confeccionado para uma pesquisa de Mestrado já concluído ${ }^{1}$. Ademais, sugerimos breve debate sobre o movimento de transcendência que as publicações invocam à arte de ser, estar e devir da Literatura Brasileira Contemporânea, estendendo-se à formação leitora. Teóricos tais como Michèle Petit, Teresa Colomer e Zygmunt Bauman são responsáveis por nos conduzir rumo à apreciação desse panorama literário conectado e transfigurado.

Para além do presente texto introdutório, há seções dedicadas à apresentação do levantamento antes mencionado, bem como das divergências observadas entre as fichas catalográficas e os conteúdos literários, além das discussões que desse acontecimento emergem. Por fim, não tarde, as considerações finais, jamais aptas a esgotar o debate, porém, necessárias à sistematização das ideias e à exposição de perspectivas atuais.

\section{OS LIVROS DE BLOGUEIROS E YOUTUBERS: UM MAPEAMENTO}

O livro em seu formato impresso jamais experienciara estar sob tantos holofotes como quando protagonizou, junto de seus autores, espaços nas estantes pertencentes às

\footnotetext{
${ }^{1}$ Este artigo traz ao saber os achados provenientes de pesquisa de Mestrado concluído no ano de 2018. Ademais, apresenta algumas constatações oriundas de tese de Doutorado em andamento. 
livrarias físicas e virtuais, aos leitores e aos estandes dos eventos e festivais literários. Desde a constatação de que a Internet também poderia vir a acrescer à produção livresca - ainda que apenas no que tange aos números ${ }^{2}$-, a Literatura tem sido eloquentemente celebrada e, nesse ínterim, redescoberta. Afinal, concedera-se voz a sujeitos cuja força de comunicação lhes era permitida exercer somente no ciberespaço, mas nem mesmo por essa razão estiveram presos às arestas das telas ou aos layouts das redes sociais.

Quando as primeiras publicações em papel assinadas por produtores de conteúdo digital foram apresentadas ao público a partir dos anos de 2010, a Literatura Juvenil de origem nacional encontrava-se ainda representada por alguns poucos nomes que a ela dedicavam os seus muitos esforços desde anos a fio: de Liliane Prata a Sérgio Klein, alcançando, mais tarde, Thalita Rebouças e Paula Pimenta, a expressão literária voltada aos jovens fora solapada por agendas e diários que preconizavam a ficcionalização do cotidiano certamente vivenciado, dia a dia, por cada um deles. Não empregamos, aqui, um tom de desprezo, dotado de pouco convencimento quanto à real importância dessas produções que se tornaram populares entre os leitores adolescentes no início do milênio. Devemos, aliás, reconhecer o lugar de destaque que obtiveram esses títulos no âmbito do mercado editorial de livros junto ao seu grupo-alvo, não somente à sua época de luz, mas também e, em especial, nesta contemporaneidade, na qual os jovens consumidores, já acostumados a escutar a fala das celebridades virtuais as quais aprenderam a admirar post após post, vídeo após vídeo, like seguido de like, proporam irromper as fronteiras das telas de seus dispositivos eletrônicos, estabelecendo-se, enfim, no campo literário, apesar de hoje imergirem nos produtos textuais da autoria de seus ídolos: adolescentes, internautas, escritores de Literatura e, às vezes, por que não, também aborrescentes.

Como parte integrante de nossa pesquisa de Mestrado, delineamos uma espécie de mapa composto por dados relativos aos livros impressos de blogueiros e youtubers lançados entre janeiro de 2008 e dezembro de 2016. Esse mapear se prestou a nos trazer uma visão ampla e demasiada geral em relação à produção literária desses internautas, com especial enfoque nos títulos comercializados sob o formato tradicional de papel. Por isso, reconhecemos que esse mapeamento, quando manufaturado, não se constituíra apto a nos demonstrar especificidades sobre este ou aquele título, até mesmo porque o objetivo de sua feitura fora pautado no princípio de que almejávamos visualizar cenário de caráter global acerca da absorção dos conteúdos virtuais assinados por celebridades do meio online por parte do mercado editorial de livros. Logo, a prerrogativa máxima

\footnotetext{
${ }^{2}$ Excluímos desse argumento as viabilidades de produção e publicação de narrativas eletrônicas, as quais, em razão da complexidade que as guarda, merecem um estudo apropriado às suas especificidades.
}

Revista X, v. 16, n. 3, p. 942-960, 2021. 
desse levantamento embasou-se em aspectos quantitativos, uma vez que as categorias de organização utilizadas a fim de listar os dados foram título, autor, editora, ademais, redes sociais das quais o blogueiro ou o youtuber se originara, não apresentando, essas tais categorizações, vinculação alguma a um suposto panorama de cunho qualitativo.

Aproveitamos esse ensejo a fim de clarificarmos que alguns livros seguramente não foram inclusos no mapeamento. Não obtivemos acesso à totalidade dos catálogos de lançamentos das grandes, médias ou pequenas editoras, porque a pesquisa considerou como fonte de dados o acesso às diversas mídias sociais administradas por internautas reconhecidos no meio, dinâmica essa que nos conduziu a contatar a produção literária de outros produtores de conteúdo, detentores de menor alcance ou popularidade, o que cooperou à expansão do contingente de obras por fim eleito à análise proposta.

À exemplo disso, apresentamos, a seguir, uma ilustração sistematizada no que se refere ao montante de livros impressos da autoria dos sujeitos de interesse para o estudo. A não ser por um breve decrescimento observado nos cinco primeiros anos presentes no mapeamento, notamos o progressivo crescimento das publicações de papel, atingindo o seu ápice no último ano da pesquisa, com cento e cinco achados (Gráfico 1).

Gráfico 1: Publicações impressas de internautas adolescentes entre 2008 e 2016.

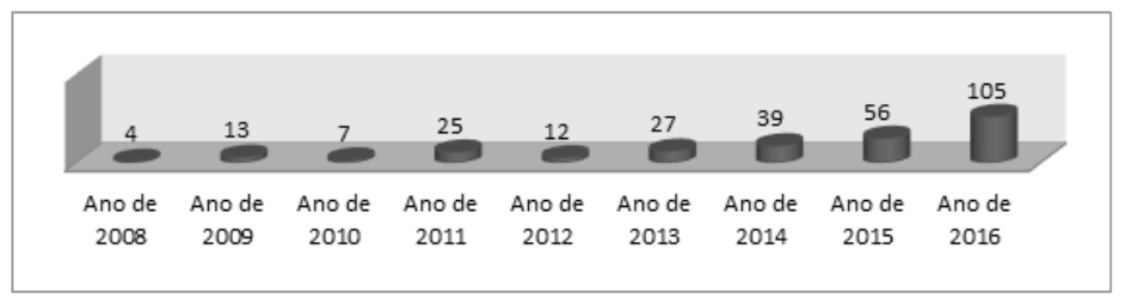

Fonte: Autoria própria.

A partir de análise das informações obtidas no decorrer desse processo, pudemos constatar a criação de selos editoriais por tradicionais grupos do ramo e, por outro lado, a expansão de pequenas e médias editoras, as quais conceberam a dinâmica de adaptar e transpor materiais virtuais de jovens navegantes ao mundo da Literatura impressa como um evento de suma importância à transformação das práticas de acesso e consumo à arte literária. Assim sendo, aproveitaram-se do movimento empreendido por concorrentes do mercado a fim de que pudessem atrair administradores de blogs e canais do YouTube à possibilidade de fazerem-se presentes em outro e até então inusitado suporte, o livro. Em uma extremidade, os nomes consagrados: Companhia das Letras, Record e Rocco. $\mathrm{Na}$ outra, aqueles que ainda intentam conquistar um lugar ao sol junto ao público jovem Revista X, v. 16, n. 3, p. 942-960, 2021. 
- e talvez já até o tenham feito com êxito, dado os anos transcorridos desde a pesquisa: Astral Cultural, Belas Letras, Évora, Giostri, Hyria, Matrix, Planeta e Panda Books.

Enveredando-nos pelas possíveis trilhas dessa nova tendência e vertente literária, deparamo-nos também com outros interessantes tópicos de observação. Percebemos um expressivo número de livros produzidos por influenciadores provenientes de diferentes redes sociais, assinados em parceria, assim como a obra $O$ amor nos tempos de \#likes (Galera, 2016), de Pâmela Gonçalves e companhia. Essa prática evidencia a necessidade de fortalecimento dos seus instrumentos de trabalho, tendo em vista a possibilidade de expansão dos inscritos ou visitantes e, por conseguinte, também dos admiradores dos conteúdos que compartilham. Nessa seara, averiguamos, ainda, o estreitamento de laços entre celebridades digitais e escritores já há muito conhecidos do público adolescente, outrora os únicos produtores de Literatura voltada à parcela jovem da população leitora. Portanto, o que antes ocorria apenas entre os autores, como foi o caso relativo ao título Ela disse, ele disse: o namoro (Rocco Jovens Leitores, 2013), de Thalita Rebouças, muito popular entre os adolescentes, e Maurício de Sousa, quadrinista que nesse projeto emprestara seus personagens da Turma da Mônica Jovem para ilustrar a narrativa, passa agora a se figurar comum a união entre jovens internautas e escritores já consagrados. Um exemplo a ser mencionado equivale ao livro Turma da Mônica jovem: uma viagem inesperada (Nemo, 2016), da autoria de Bárbara Dewet e outras blogueiras e youtubers, além das ilustrações e finalização artística do referido desenhista. Tal dinâmica auxilia a difusão do trabalho dos navegantes, além da sobrevivência dos autores mais antigos no ramo, bem como a renovação do público-alvo de seus registros, uma vez apresentados à nova geração de leitores da era eletrônica. Ademais, personalidades do cenário artístico, entre atores e músicos, lançaram as suas próprias obras em união a nomes apreciados no nicho juvenil, os quais encontravam-se, pelo menos à época da pesquisa, em ascensão. A duologia $O$ reino das vozes que não se calam (Fantástica, 2014) e $O$ mundo das vozes silenciadas (Fantástica, 2015), de Sophia Abrahão, atriz e cantora, e Carolina Munhóz, escritora de Literatura Fantástica, corresponde a um dos diversos exemplares do gênero.

A percepção quanto à diversidade de gêneros literários abarcados pelos livros em destaque é algo a ser melhor explorado na próxima seção do artigo, considerando o mote principal do presente estudo: a divergência entre dados catalográficos e conteúdos.

\section{AS MIL "FICHAS" DA LITERATURA JUVENIL BRASILEIRA}

Diferentes dos livros há tempos comercializados à população juvenil, as obras de blogueiros e youtubers apresentaram frescor ao seu público-alvo, mas, sobretudo, à 
própria Literatura e à ramificação do mercado que a acolhe. Se outrora os formatos de agendas e diários escritos por adultos de meia idade narravam as histórias relativas aos adolescentes restritos à ficcionalidade (Figura 1), hoje, esses títulos são assinados pelos próprios protagonistas de tal nicho. Quando tomada por força, a Web, para além de suas tantas e outras relevantes atribuições, também tornara-se imbuída de admitir específico espaço à confissão, inicialmente via chat e blog e, mais tarde, por intermédio das redes sociais cujas gêneses se deveram à necessidade de transcender barreiras do mundo físico e dos próprios corpos. O caráter confessional concedido aos blogs, também populares enquanto diários virtuais, é o que em grande parte responsabilizou-se por dinamizar a interação entre os pares, possibilitando-os compartilhar aflições, anseios e alegrias sob a forma de textos adornados por recursos diversos, entre imagens, áudios e vídeos, não muito distantes do empenho de confecção vinculado ao papel. Atualmente, a partilha de assuntos caros à população mais jovem é também efetivada por intermédio do YouTube, desmistificando a transição sem retorno que a cultura impressa impugnara à cultura oral. O que percebemos é o resplandecer da oralidade secundária ${ }^{3}$, que conhece a escrita e se integra como tal justo porque nela se embasa e dela vem à tona (ONG, 1998, p. 154).

Figura 1: Alguns títulos literários brasileiros demasiados populares entre os adolescentes na primeira década dos anos 2000 .
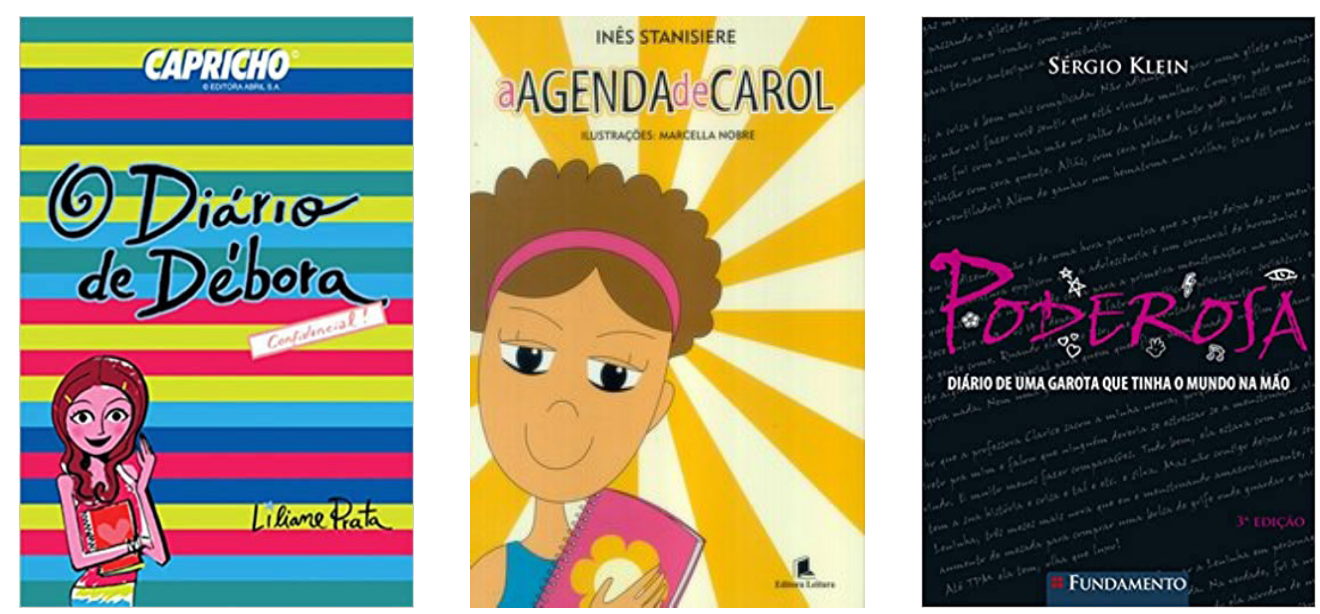

O diário de Débora (Marco Zero, 2003), de Liliane Prata; A agenda de Carol (Leitura, 2004), de Inês Stanisieri; Poderosa: diário de uma garota que tinha o mundo na mão (Fundamento, 2006), de Sérgio Klein.

Fonte: Google.

\footnotetext{
${ }^{3} \mathrm{~A}$ oralidade secundária diz respeito àquela sustentada pelo advento das novas tecnologias. 
O adolescente, então, pudera se debruçar e se deleitar nesse microespaço criado e a ele ofertado, pois a sua voz o jovem sujeito sempre sustentara. Condição de caráter obrigatório, o nascimento e o reconhecimento da adolescência aconteceu no século XX, desfazendo-se da terminologia juventude, já que no âmbito dessa ocorrência a velhice fora desvalorizada, e a idade adulta, então, submetida ao processo de rejuvenescimento (MORIN, 1997, p. 154). Assim, restou àquele que se equilibra na linha que segrega os prazeres da infância e os compromissos da adultice, adolescer. A adolescência, por isso, é entendida enquanto construção sociocultural; moratória cuja conjuntura na qual se faz existir, assinalada pelo consumo, espetáculo e entretenimento, é protelada e torna-se interminável (CALLIGARIS, 2000, p. 16). O adolescente brasileiro e contemporâneo, especialmente o sujeito que crescera e conivera com o fenômeno das novas tecnologias conectadas a uma inter-rede, o jovem nativo digital de Prensky (2001), viu-se defronte a ambivalência de seu próprio estado de ser e estar, ora analógico, ora digital, imposto pela chegada do século XXI, hospedeiro gentil dos blocos de anotações e das abas dos calorosos e multimodais diálogos empreendidos no meio online, do ICQ ao What's App.

Transcorreram-se anos, e nesses, as culturas de mídia e massa, intensificadas pelo sobreviver da rede, alcançaram a arte do manufaturar literário. Como sabemos, este artigo não pretende discorrer acerca do impacto dos artifícios eletrônicos à prática da escrita ou da leitura, o que pode ser facilmente verificado a partir de breve vislumbre em relação às plataformas virtuais de autopublicação, múltiplas no ciberespaço de uma atualidade na qual a Literatura conquista território, muitos adeptos e ávidos celebrantes. O fazer literário ao qual nos referimos compreende aquilo o que seu campo de origem, tradicionalmente sustentado sobre os pilares do suporte físico de papel, demonstrara estar disposto a abrigar nas páginas de celulose desvirginadas, de gramatura sofisticada.

A Literatura da autoria de internautas adolescentes, os blogueiros e youtubers, é um sintoma da conectividade de nossos tempos, a cada clique ou toque mais necessária; imprescindível por natureza na temporalidade corrente, assim como as transfigurações que a Literatura Eletrônica sugere aos espectadores contemporâneos adoradores ou não das inovadoras faces da $W e b$, ao menos reconhecedores de que a revolução tecnológica transfigurou os lugares de existência e coexistência da prática do narrar. Sintomático é, também, a hibridez que demarca a diversidade das publicações desses jovens autores, outrora encarregados apenas da manufatura de conteúdos exclusivos aos seus canais de comunicação no ambiente digital. Convidados por editoras brasileiras para publicarem livros que levam os seus nomes nas capas e lombadas, os tais navegantes se aventuram no vasto universo que a Literatura guarda, acima de tudo, no que concerne às muitas 
possibilidades de manufaturá-la no meio impresso. O quadro que se elabora não é algo demasiado surpreendente. Afinal, os inúmeros blogueiros e youtubers atuantes em suas respectivas áreas, produtores de materiais heterogêneos, são proporcionais em termos da abundância e do sortimento quanto aos gêneros dos títulos literários que agora assinam.

O minucioso exame das fichas catalográficas pertencentes a alguns dos livros da autoria de influenciadores digitais presentes no levantamento realizado, viabilizou-nos constatar as divergências entre as estruturas de gênero trazidas ao público pelas obras e a classificação proposta pelas editoras que as publicaram e lançaram-nas no mercado.

Foram selecionados registros coletados a partir do mapeamento, os quais foram distribuídos com base em seus conteúdos em quatro grupos dos gêneros literários mais comuns entre as publicações impressas analisadas, a saber: interativo, manual, crônica e relato autobiográfico (Tabela 1). Isso, pois as narrativas ficcionais, graphic novels e os poemas não trouxeram evidências em relação às divergências de categorizações.

Tabela 1: Divergências entre gêneros identificados e fichas catalográficas.

\begin{tabular}{|c|c|c|}
\hline Gênero identificado & $\begin{array}{c}\text { Dados das obras literárias } \\
\text { impressas }\end{array}$ & $\begin{array}{l}\text { Informações das fichas } \\
\text { catalográficas }\end{array}$ \\
\hline \multirow[b]{2}{*}{ Interativo } & $\begin{array}{l}\text { As coisas mais legais do mundo } \\
\text { (PINHEIRO, Verus, 2016) }\end{array}$ & 1. Crônica Brasileira \\
\hline & $\begin{array}{c}\text { O sensacional livro } \\
\text { antitédio do Lucas Rangel } \\
\text { (RANGEL, Paralela, 2016) }\end{array}$ & $\begin{array}{l}\text { 1. Blogs (Internet) } \\
\text { 2. Comunicação Digital } \\
\text { 3. Internet } \\
\text { 4. Redes Sociais } \\
\text { 5. YouTube } \\
\text { (Recurso Eletrônico) }\end{array}$ \\
\hline \multirow{2}{*}{ Manual } & $\begin{array}{l}\text { Manual de sobrevivência } \\
\quad \text { do adolescente } \\
\text { (LOURES, Astral Cultural, 2016) }\end{array}$ & $\begin{array}{c}\text { 1. Autoajuda } \\
\text { 2. Autoconhecimento } \\
\text { 3. Encorajamento (Psicologia) }\end{array}$ \\
\hline & $\begin{array}{c}\text { Amiga, deixa de ser trouxa } \\
\text { (CAMARGO; OLIVEIRA, } \\
\text { Matrix, 2016) }\end{array}$ & $\begin{array}{l}\text { 1. Relação Homem-Mulher } \\
\text { 2. Humor, Sátira, Etc. } \\
\text { 3. Sexo - Humor Sátira, Etc. }\end{array}$ \\
\hline
\end{tabular}




\begin{tabular}{|c|c|c|}
\hline \multirow[b]{2}{*}{ Crônica } & $\begin{array}{c}\text { A menina que } \\
\text { colecionava borboletas } \\
\text { (VIEIRA, 2013, Gutenberg) }\end{array}$ & 1. Literatura Juvenil \\
\hline & $\begin{array}{c}\text { Faça amor, não faça jogo } \\
\text { (CARVALHO, 2014, Gutenberg) }\end{array}$ & $\begin{array}{c}\text { 1. Autoajuda } \\
\text { 2. Amor } \\
\text { 3. Autoconsciência } \\
\text { 4. Reflexões }\end{array}$ \\
\hline \multirow{2}{*}{$\begin{array}{l}\text { Relato } \\
\text { autobiográfico }\end{array}$} & $\begin{array}{c}\text { Eu fico loko } \\
\text { (FIGUEIREDO, } \\
\text { Novas Páginas, 2015) }\end{array}$ & 1. Crônicas Brasileiras \\
\hline & $\begin{array}{c}\text { Diário de um } \\
\text { adolescente apaixonado } \\
\text { (MOREIRA, Novas Páginas, 2015) }\end{array}$ & 1. Ficção Brasileira \\
\hline
\end{tabular}

Fonte: Autoria própria.

Para facilitar a explanação sobre as informações obtidas, organizamos os textos em diferentes tópicos, tomando como pauta os gêneros observados durante as leituras.

\section{Gênero identificado: interativo}

Por apresentarem estrutura diferenciada e interface participativa comparando-os às demais obras literárias, os livros categorizados como interativos não trazem em suas fichas catalográficas quaisquer dados indicadores do inusitado caráter o qual assumem. As coisas mais legais do mundo (Verus, 2016), de Karol Pinheiro, é considerado por sua editora como uma compilação de crônicas, mesmo que a estrutura sugerida pela autora em nada se assemelhe ao conceito do gênero comumente trazido pela Teoria Literária.

Situação análoga acontece com o empreendimento literário de Lucas Rangel, O sensacional livro antitédio do Lucas Rangel (Paralela, 2016), já que em detrimento de exprimir a faceta interativa que apresenta aos leitores, restringe-se a norteá-los com termos vinculados ao ciberespaço e à cibercultura, tais como Internet, blogs e YouTube. Embora pertinentes, haja vista as origens do autor e o contexto de produção de seus conteúdos, as menções selecionadas por sua editora não esclarecem o real teor da obra. 


\section{Gênero identificado: manual}

Da autoria de Camila Loures, o Manual de sobrevivência do adolescente: os spoilers que ninguém te contou (Astral Cultural, 2016), é classificado como obra de autoajuda e autoconhecimento, ademais, como sendo tocante também ao campo de estudo relativo à Psicologia, já que enaltece a prática do encorajamento pessoal. Ainda que a obra esteja repleta de dicas e instruções sobre específico tema e, para além dessas prerrogativas, também conduza debates à subjetividade e às facetas emocionais próprias à fase da adolescência, não apresenta o gênero manual devidamente expresso na ficha catalográfica, mas, ao contrário, outra definição especificamente relativa à autoajuda.

Também nesse contexto, a ficha pertencente à Amiga, deixa de ser trouxa: o manual de relacionamento da diva depressão (Matrix, 2016), livro de Eduardo Camargo e Filipe Oliveira, disponibiliza aos leitores informações superficiais quanto ao conteúdo abordado, deixando claro somente aspectos gerais contemplados pelo texto, entre eles, as relações estabelecidas entre homens e mulheres, entre outras atinentes à temática.

\section{Gênero identificado: crônica}

Apesar do título A menina que colecionava borboletas (Gutenberg, 2013), de Bruna Vieira, ter sido dedicado especialmente ao público adolescente, o que justifica, portanto, a classificação da obra como circunscrita à Literatura Juvenil, sua ficha não traz expresso o gênero crônica que melhor ilustraria os registros nele abarcados.

Intitulado Faça amor, não faça jogo (Gutenberg, 2014), livro de Ique Carvalho, também não exprime o gênero literário relativo à crônica. Ao invés disso, apresenta uma lista dos campos temáticos acerca dos quais os conteúdos de seus textos abordam, tais como autoajuda, amor, autoconsciência, além de reflexões gerais e diversas.

\section{Gênero identificado: relato autobiográfico}

O livro Eu fico loko: as desaventuras de um adolescente nada convencional (Novas Páginas, 2015), assinado por Christian Figueiredo, embora concebido por sua editora como compilação de crônicas e seja de conhecimento que o universo relativo ao supracitado gênero possa contemplar os relatos autobiográficos, essa classificação seria mais adequada se estivesse se referindo apenas à estrutura de organização da obra, pois o cerne de sua escrita possui tendências de inclinação ao âmbito da autobiografia. 
Essa tal questão também é percebida em Diário de um adolescente apaixonado (Novas Páginas, 2015), da autoria de Rafael Moreira, tendo sido catalogada, a obra, como ficção brasileira, apresentando um conjunto de registros de cunho autobiográfico. Aliás, esse corresponde a um dos títulos aptos a ilustrar um interessante fenômeno que podemos observar no domínio das publicações de papel, pelo menos no que diz respeito ao compartilhamento de experiências e vivências do adolescer em formato semelhante àquele colocado em prática nos diários convencionais, com direito a fotos e desenhos, além de textos escritos sob diferentes fontes e linguagem despretensiosa (Figura 2).

Figura 2: Páginas do livro do youtuber Rafael Moreira.
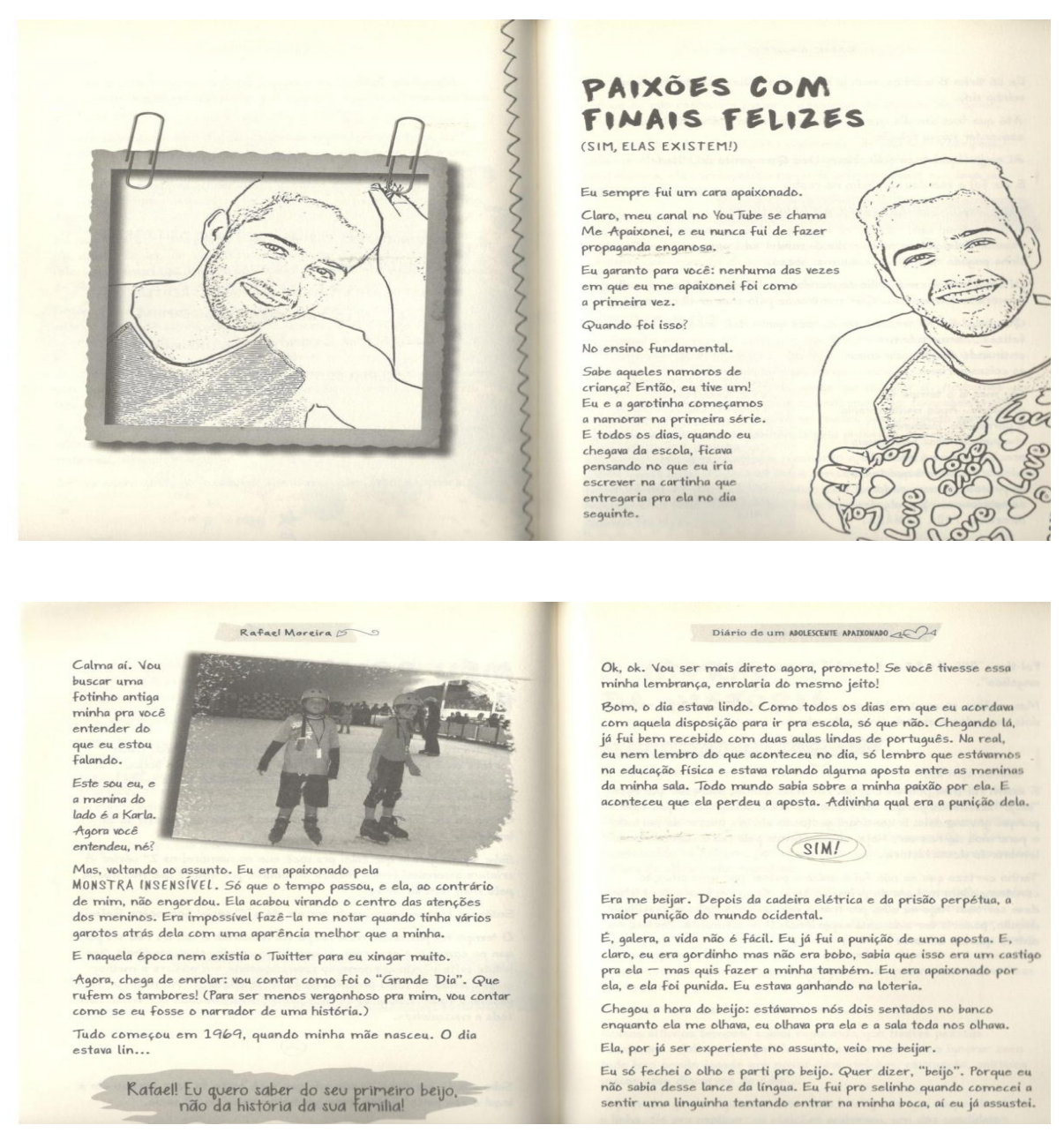

Fonte: MOREIRA, Rafael. Diário de um adolescente apaixonado.

São Paulo: Novas Páginas, 2015, p. 72-73; 88-89. 
Depreendemos, por parte das editoras, dificuldade ou opção deliberada ambas vinculadas à inadequada categorização dos gêneros e espaços ocupados por materiais produzidos por blogueiros e youtubers adolescentes, os autores dos livros em voga.

Em alguns casos particulares, define-se não a obra, mas sim o autor. Tal como nos fora oportunizado constatar por intermédio da análise da ficha catalográfica do livro de Lucas Rangel, a dinâmica de lançamento dos títulos juvenis impressos trouxe à tona uma nova forma de classificação, vide o emprego de termos vinculados à cibercultura blogs, YouTube e expressões afins. Em Muito mais que cinco minutos (Paralela, 2015), da autoria de Kéfera Buchmann, é possível averiguar o uso de vocábulos classificatórios similares àqueles utilizados no título literário de Rangel. Inclusive, ambas as produções foram publicadas pela mesma editora e por meio do mesmo selo editorial. Outrossim, esse fato auxilia-nos a refletir com relação a certa padronização das fichas catalográficas presentes nas obras encabeçadas por escritores advindos de cenário comum a todos eles, apesar de tocantes a distintas temáticas ou contemplativas dos mais diversos gêneros. Faz-se preciso esclarecer que embora esse movimento possa ter se tornado evidente ao nos reportarmos aos supracitados empreendimentos do ramo literário, esclarecemos que esse claro panorama não se configura convenção seguida por editoras brasileiras: a obra assinada pelo youtuber Luis Mariz, Fala galeraaa! (Astral Cultural, 2015), uma espécie de relato autobiográfico, traz em sua ficha catalográfica classificações convenientes ao seu conteúdo, indicando o gênero ao qual está circunscrito, além de outras elucubrações tangentes aos temas que protagonizam as pautas de seus vídeos presentes no YouTube.

Essas ponderações tornam caro refletir sobre a divulgação e a comercialização de livros impressos produzidos por celebridades adolescentes do ciberespaço enquanto detentores de registros autobiográficos. Uma atenção de caráter reforçado deve então ser concedida a essa dinâmica e peculiar tendência do mercado editorial de livros, uma vez que por mais que as editoras invistam na publicidade de seus produtos como atinentes à seara de relatos autobiográficos, ainda sim não os concebem, no ato das categorizações, enquanto tais - ou ao menos conforme sugerem definições ditas clássicas e tradicionais. Entretanto, acreditamos que essas divergências possam encontrar sua origem para além das problemáticas de cunho editorial, também na contemporaneidade líquida e digital, cujos pilares encontram-se sob constante processo de reconstrução (BAUMAN, 2001). A partir da dissolução humana no mar de mercadorias, o que colaborou à transformação do homem como produto passível de apreciação e comércio (BAUMAN, 2008, p. 20) e, como consequência, à sua própria mutação como coisa, tornando-se totalmente entregue 
ao consumo desenfreado e sistemático de objetos que a moda e a publicidade impõe-lhe cotidianamente (LLOSA, 2013, p. 20), a Literatura viu-se obrigada a se transfigurar.

O esvaziamento da vida interior, ocorrido em decorrência da superficialidade de uma amosfera na qual a prática do capitalismo é semeada e cria raízes tão fortes quanto os sustentáculos da sociedade contemporânea (BAUMAN, 2008, p. 20), contribuiu para o esvanecimento da liberdade individual e coletiva, assim conforme Llosa (2013, p. 22) justifica: "[...] as trocas que ocorrem não são resultado de escolhas livres das pessoas, mas do sistema econômico, do dinamismo do capitalismo [...]”. Sendo assim, no berço da civilização do consumo e espetáculo, uma nova Literatura dedicada tanto às crianças quanto aos adolescentes nasce, é aninhada e recebe acolhimento da mídia e do mercado. Isso se deve, segundo Colomer (2017, p. 189), ao aumento da escolaridade de ambos os grupos etários, bem como para satisfazer demandas do ócio e da crescente necessidade de entretenimento, há tempos presentes quando o boom das novas tecnologias ocorrera.

O primeiro momento de experimentação acontecera na pretérita década de 1970, estendendo-se aproximadamente por dez anos em virtude do desenvolvimento cultural, político e econômico inerente à conversão das sociedades ocidentais em pós-industriais, ainda durante os anos de 1960. A calmaria instaurada em 1990 sofrera grande desatino quando houve a passagem para o novo milênio, trazendo junto a ele várias novidades "[...] nas inter-relações entre texto e imagem, ficções audiovisuais, digitais, etc. [...]" (COLOMER, 2017, p. 189). É daí que advém essa inusitada gama de títulos literários, providos dos mais diversos temas, concernentes aos mais distintos gêneros. Entre eles, alguns dos quais descritos pela estudiosa em destaque, livros cuja construção emprega a estrutura narrativa e informativa, com altas doses de autoajuda e humor, colaborando à mantença de interesses peculiares à idade e ao desejo de conhecer sobre algo ou alguém - panorama similar àquele que se refere a expressiva parcela dos livros que analisamos. Isso, sem contabilizar os bônus oferecidos pela convergência midiática à Literatura, fato que implicaria na elaboração de estudo acadêmico específico, dada a sua complexidade.

Talvez seja por essa razão que a Literatura Juvenil Contemporânea, em especial a manufatura de origem nacional, conforme preconiza-nos Gregorin Filho (2011, p. 42), tem procurado proporcionar aos seus leitores, em comum acordo ao mercado editorial, uma produção plural, possuidora de faces diversificadas, e não expressão que objetiva a veiculação rígida de padrões culturais, estéticos ou moralizantes, a título de ilustração. Não que as produções de autores juvenis populares na década de 1980, como é o caso de Lygia Bojunga ou Pedro Bandeira, por exemplo, trabalharam em prol do reforço de moldes aos quais os adolescentes em formação deveriam se enquadrar. Essa ocorrência 
nem mesmo pode ser percebida nos livros de escritores dos anos 2000, acerca dos quais já tivemos a oportunidade de aqui discorrer. Pelo contrário, intentaram abordar em suas obras questões além de relevantes ao público pretendido, também caras ao adolescer de cada um de seus leitores: os embates entre pares e familiares, as decepções amorosas, as dificuldades em relação ao desenvolvimento das tarefas de casa ou de natureza escolar, e a incompreensão quanto ao poderio das figuras autoritárias. E mais do que tocar neste ou naquele tópico, demonstraram um mundo de possibilidades reais a partir da criação de universos ficcionais ou situações hipotéticas, expondo-lhes a sentidos e sentimentos importantes à formação de caráter, preparando-os como cidadãos críticos e conscientes:

Os leitores adolescentes têm, pois, a possibilidade, tanto de se sentirem como se estivessem em casa com a leitura das narrativas que falam de uma idade mínima vivida em um tempo e um modo de vida comum, como de se sentirem fascinados pela descrição de situações muito cariadas e afastadas de seu contexto habitual. Ambas as coisas ocorrem em um momento de sua vida em que necessitam e buscam o desafio de mostrarem-se ao mundo mais longínquo e variado para definirem-se eles mesmos em sua identidade pessoal (COLOMER, 2017, p. 242).

Sob essa redoma, a produção literária impressa de autoria dos jovens blogueiros e youtubers serve como uma espécie de mola propulsora aos trabalhos outrora iniciados pelos demais indivíduos que dedicaram suas escritas aos adolescentes. Todavia, agora, o espirituoso dia a dia desses leitores pode finalmente ser experienciado através dos olhos daqueles com os quais compartilham além da faixa-etária e características em comum, também as lembranças de um passado não muito distante, aquilo que os aflige no tempo presente, ademais, as ansiosas perspectivas para o futuro, no qual ser adolescente já não lhes cabe, mas assumir os encargos como adulto, os aterrorizam. Entendamos os autores adolescentes, portanto, enquanto transmissores culturais, responsáveis, de acordo com Petit (2019, p. 23), por construir e ofertar mundos habitáveis, “[...] poder encontrar ali o seu lugar e locomover-se; celebrar a vida no cotidiano, oferecer as coisas poeticamente; inspirar as narrativas que cada pessoa fará de sua própria vida [...]" - ler, saber e viver.

Retomando a pauta de discussão sobre a divergência observada entre os gêneros trazidos por livros impressos de jovens internautas e suas fichas catalográficas, é preciso ressaltarmos que essa discrepância em relação à categorização de gêneros dos títulos inclusos na tabela anteriormente colocada em exposição e seus reais teores não deve ser generalizada, mas somente considerada plausível para eventuais averiguações. Afinal, o mapeamento de dados confeccionado apresenta contingente de obras muito mais amplo e, junto a elas, consequentemente, outras tantas informações que demandam adequado Revista X, v. 16, n. 3, p. 942-960, 2021. 
desbravamento. Existem inúmeros pontos de partida para pensarmos sobre a confecção das fichas catalográficas. Oficialmente, elas deveriam ser atribuição dos profissionais da área da Biblioteconomia - os bibliotecários. Entretanto, será que todas essas editoras puderam contar com a presença de especialistas capacitados em seus quadros técnicos? E ainda, até que ponto as questões de política ou interesse da editora não influenciaram o processo de categorização dos conteúdos das obras, refletido nas já referidas fichas? Essas são algumas inquietações prudentes e viáveis ao contexto de debate apresentado. Por outro lado, bem como exposto por Soares (2007, p. 77), faz-se relevante reforçar o argumento de que não necessariamente os livros aos quais nos debruçamos contemplam aspectos que se referem a um único gênero. É preciso que examinemos os textos sempre de modo aberto e inconclusivo, respeitando os caminhos que os pertencem a fim de que nos tornemos capazes de explorar suas trilhas, objetivando alcançar os seus potenciais.

\section{CONSIDERAÇÕES FINAIS}

A Literatura assinada por adolescentes navegantes do ciberespaço, produtores de seus próprios conteúdos na Internet, desestabilizou todo o sistema literário, incluindo as crenças apocalípticas acerca do futuro da arte de escrever, publicar e inspirar sujeitos. Claramente, reconhecemos a existência quanto às estratégias de marketing que existem por detrás do lançamento de obras impressas da autoria dessas tais celebridades digitais: mais um produto vinculado aos seus nomes e legados virtuais. O licenciamento do fazer literário interessa-nos no sentido de que os livros de blogueiros e youtubers sejam de fato capazes de tocar e conduzir os seus leitores ao contato com seus iguais, mas acima de tudo, consigo próprios. Pois, é a partir desse movimento de ir e vir de si para o outro que o real impacto da Literatura em suas vidas poderá se constituir possível e legítimo.

É de nosso conhecimento, ainda, que a reprodutibilidade técnica da arte e afins, eximiamente descrita por Benjamin (2013), é condição circunstancial e indispensável ao retrato da sociedade a qual surgira após a Revolução Industrial, com seus maquinários e consequentes novas formas de produção, comércio, troca e garimpo. No ramo literário, a reprodução da Literatura tornara-se banal: um número cada vez maior de exemplares integram as tiragens dos novos títulos colocados à disposição do público, servindo como chamariz aos pretensos consumidores ou leitores, uma vez que para além da assinatura do produto em questão ser considerada fator de extrema importância no julgamento da qualidade do objeto desejado (COMPAGNON, 1996, p. 97), o teor quantitativo atrelado à tal manufatura, especialmente após a revolução eletrônica, exerce expressivo impacto 
na decisão final a respeito da aquisição da obra ou do dispêndio de tempo sobre o que o seu conteúdo tem a oferecer, em vias contrárias à estética (SARLO, 1999, p. 150).

Nesta atual temporalidade, o meio editorial passa por um processo de mutação, sobretudo no que tange à produção veiculada ao público majoritariamente constituído por adolescentes. Aparenta estar se adaptando às novas demandas e sugestões advindas dos jovens leitores, cujo próprio processo de desenvolvimento, fortemente influenciado pela gênese das novas tecnologias digitais conectadas a uma inter-rede, conduzira-os a intentar lograr espaços dotados de maior especificidade em relação às suas trajetórias vide o nascimento de novos gêneros juvenis, dentre eles, o Young Adult e o New Adult. Essa grande miscelânia de termos e expressões utilizados para caracterizar os livros dos jovens influenciadores digitais é trazida à tona como sintoma da conectividade do tempo presente, mas também, assim cremos verdadeiramente, enquanto reflexo da vasta gama de possibilidades de dar vida à Literatura perante o espectro de temáticas e das formas por meio das quais podem ser abordadas no ciberespaço e para além dele. Partindo dos relatos autobiográficos e alcançando as crônicas, todos cumprem um mesmo propósito, independentemente da maneira por meio da qual têm sido categorizados: conceder voz à adolescência, oferecer perspectivas de mundo aos leitores, e demonstrar, nesse contexto, que a produção literária juvenil pode mais, esteja ela circunscrita ou não à tradição.

\section{REFERÊNCIAS}

ABRAHÃO, Sophia; MUNHÓZ, Carolina. O reino das vozes que não se calam. Rio de Janeiro: Fantástica, 2014.

ABRAHÃO, Sophia; MUNHÓZ, Carolina. O mundo das vozes silenciadas. Rio de Janeiro: Fantástica, 2015.

BAUMAN, Zygmunt. Modernidade líquida. Rio de Janeiro: Zahar, 2001.

BAUMAN, Zygmunt. Vida para consumo: a transformação das pessoas em mercadoria. Rio de Janeiro: Zahar, 2008.

BENJAMIN, Walter. A obra de arte na era de sua reprodutibilidade técnica. Porto Alegre: L\&PM, 2013.

BUCHMANN, Kéfera. Muito mais que cinco minutos. São Paulo: Paralela, 2015.

CALLIGARIS, Contardo. A adolescência. São Paulo: Publifolha, 2000. 
CAMARGO, Eduardo; OLIVEIRA, Filipe. Amiga, deixa de ser trouxa: o manual de relacionamento da diva depressão. São Paulo: Matrix, 2016.

CARVALHO, Ique. Faça amor, não faça jogo. Belo Horizonte: Gutenberg, 2014.

CELESTE, Jennifer da Silva Gramiani. O livro nos tempos de \#likes: transfigurações na literatura brasileira contemporânea. 239 f. 2018. Dissertação (Mestrado em Letras) - Centro de Ensino Superior de Juiz de Fora, Juiz de Fora, 2018.

COLOMER, Teresa. Introdução à literatura infantil e juvenil atual. São Paulo: Global Editora, 2017.

COMPAGNON, Antoine. Os cinco paradoxos da modernidade. Belo Horizonte: Editora UFMG, 1996.

DEWET, Bárbara et al. Turma da Mônica jovem: uma viagem inesperada. Belo Horizonte: Nemo, 2016.

FIGUEIREDO, Christian. Eu fico loko: as desaventuras de um adolescente nada convencional. São Paulo: Novas Páginas, 2015.

GONÇALVES, Pâmela et al. O amor nos tempos de \#likes. Rio de Janeiro: Galera, 2016.

GREGORIN FILHO, José Nicolau. Literatura juvenil: adolescência, cultura e formação de leitores. São Paulo: Editora Melhoramentos, 2011.

KLEIN, Sérgio. A poderosa: diário de uma garota que tinha o mundo na mão. Curitiba: Fundamento, 2006.

LLOSA, Mario Vargas. A civilização do espetáculo: uma radiografia do nosso tempo e da nossa cultura. Rio de Janeiro: Objetiva, 2013.

LOURES, Camila. Manual de sobrevivência do adolescente: os spoilers que ninguém te contou. São Paulo: Astral Cultural, 2016.

MARIZ, Luis. Fala, galeraaa!. São Paulo: Astral Cultural, 2015.

MOREIRA, Rafael. Diário de um adolescente apaixonado. São Paulo: Novas Páginas, 2015.

MORIN, Edgar. Cultura de massas no século XX: neurose. Rio de Janeiro: Forense Universitária, 1997. 
ONG, Walter. Oralidade e cultura escrita: a tecnologização da palavra. São Paulo: Papirus, 1998.

PETIT, Michèle. Ler o mundo: experiências de transmissão cultural nos dias de hoje. São Paulo: Editora 34, 2019.

PINHEIRO, Karol. As coisas mais legais do mundo. Rio de Janeiro: Verus, 2016.

PRATA, Liliane. O diário de Débora. São Paulo: Marco Zero, 2003.

PRENSKY, Marc. Digital natives, digital immigrants. On The Horizon, oct., 2001, v. 9, n. 5, p. 1-6.

RANGEL, Lucas. O sensacional livro anti-tédio do Lucas Rangel. São Paulo: Paralela, 2016.

REBOUÇAS, Thalita; SOUSA, Maurício. Ela disse, ele disse: o namoro. Rio de Janeiro: Rocco, 2013.

SARLO, Beatriz. Cenas da vida pós-moderna: intelectuais, arte e videocultura na argentina. Rio de Janeiro: Editora UFRJ, 2000.

SOARES, Angélica. Gêneros literários. São Paulo: Ática, 2007.

STANISIERI, Inês. A agenda de Carol. Belo Horizonte: Leitura, 2004.

VIEIRA, Bruna. A menina que colecionava borboletas. Belo Horizonte: Gutenberg, 2013.

Recebido em: 08 fev. 2021.

Aceito em: 18 mar. 2021. 